\title{
Asthma control during long term treatment with regular inhaled salbutamol and salmeterol
}

D Robin Taylor, G Ian Town, G Peter Herbison, David Boothman-Burrell, Erin M Flannery, Bob Hancox, Elizabeth Harré, Keith Laubscher, Vivienne Linscott, Catriona M Ramsay, Geoff Richards, with the technical assistance of J Cowan, N Holbrook, C McLachlan, S Rigby

\begin{abstract}
Background-The adverse effects of long term treatment of asthma with the short acting $\beta$ agonist fenoterol have been established in both epidemiological and clinical studies. A study was undertaken to investigate the efficacy and safety of long term treatment with salbutamol and salmeterol in patients with mild to moderate bronchial asthma.

Methods-In a two centre double dummy crossover study 165 patients were randomly assigned to receive salbutamol $400 \mu \mathrm{g}$ qid, salmeterol $50 \mu \mathrm{g}$ bid, or placebo via a Diskhaler. All patients used salbutamol as required for symptom relief. The study comprised a four week run in and three treatment periods of 24 weeks, each of which was followed by a four week washout. Asthma control was assessed by measuring mean morning and evening peak expiratory flow rate (PEFR), a composite daily asthma score, and minor and major exacerbation rates. Washout assessments included methacholine challenge and bronchodilator dose response tests. Analysis was by intention to treat.
\end{abstract}

Otago and Canterbury Respiratory Research Groups, Dunedin and Christchurch Schools of Medicine,

University of Otago

Medical School, New

Zealand

D R Taylor

G I Town

G P Herbison

D Boothman-Burrell

E M Flannery

B Hancox

E Harré

K Laubscher

V Linscott

C M Ramsay

G Richards

Correspondence to:

Dr D R Taylor, Department

of Medicine, Dunedin

School of Medicine,

University of Otago, PO Box

913, Dunedin, New Zealand

Received 17 November 1997 Returned to authors

Returned to author 1998

Revised version received

5 May 1998

Accepted for publication

6 May 1998 dence of rebound deterioration in asthma control, lung function, or bronchial hyperresponsiveness following cessation of either active treatment, and no evidence of tolerance to salbutamol or salmeterol. Conclusions-Regular treatment with salmeterol is effective in controlling asthma symptoms and reduces minor more than major exacerbation rates. Salbutamol was associated with improved daytime symptoms but subtle deterioration in asthma control occurred over time. Salbutamol should therefore be used only as required. (Thorax 1998;53:744-752)

Keywords: asthma therapy; salbutamol; salmeterol

In the late 1980s epidemiological and clinical research carried out in New Zealand focused attention on the problem of increasing morbidity and mortality from asthma in that country, and the possibility that the use of inhaled $\beta$ agonists might be contributing to these adverse trends. In case-control studies the risk of death or near-death from asthma was shown to be significantly greater in patients prescribed inhaled fenoterol. ${ }^{1}$ Furthermore, Sears et al demonstrated that asthma control was worse in most of 64 patients receiving regular inhaled fenoterol for 24 weeks than when they received "as needed" bronchodilator. This adverse outcome was associated with a fall in baseline lung function and an increase in non-specific bronchial hyperresponsiveness (BHR). ${ }^{3}$ These findings generated the hypothesis that, despite the immediate benefits of using a $\beta$ agonist bronchodilator, the later reduction in airway calibre and increase in BHR might render patients more susceptible to triggers such as inhaled allergen or viral infection, and hence to poorer overall asthma control. ${ }^{4}$

These data provoked questions about the safety of all the short acting inhaled $\beta$ agonists. ${ }^{4}$ The results of some studies suggested that adverse changes in lung function and BHR may occur with the other short acting agents. ${ }^{5}$ Particular attention was given to "rebound" BHR immediately following cessation of treatment. ${ }^{6}$ However, at the time there were no other substantial placebo controlled studies to address questions regarding long term control of asthma during regular short acting $\beta$ agonist treatment, particularly salbutamol. ${ }^{4}$ In addition, increases in asthma morbidity and mortality were occurring in countries in which fenoterol was not widely prescribed, but where there was a progressive rise in the use of inhaled $\beta$ agonists. ${ }^{7}$ This raised the possibility that increasing use of $\beta$ agonists as a class, and not 
just fenoterol, might be contributing to adverse epidemiological trends.

Against this background the long acting agents salmeterol and formoterol became available. These drugs are very effective in controlling asthma symptoms, particularly during the night, ${ }^{8}$ and more recent evidence suggests that they confer benefit in patients with chronic asthma who remain symptomatic despite regular inhaled corticosteroid therapy. ${ }^{9-11}$ However, perhaps as a result of concerns about the short acting agents, the introduction of the long acting drugs was initially cautious. ${ }^{12}$ Large surveillance studies were carried out to evaluate possible risks of death or near-death from asthma in large populations being prescribed salmeterol. ${ }^{13}{ }^{14}$ The infrequency of adverse events was reassuring, but did not exclude the possibility that in sporadic cases death from asthma may be drug-related. ${ }^{14}$ Furthermore, there is conflicting evidence that regular use of long acting $\beta$ agonists is associated with the advent of tolerance. Although in many large studies this phenomenon has not been demonstrated, ${ }^{15} 16$ there are other reports that both bronchodilator as well as non-bronchodilator tolerance does occur. ${ }^{17} 18$ The clinical relevance of these findings remains unclear, but they raise the possibility that, despite or perhaps even because of sustained bronchodilatation, control of asthma might be adversely affected, particularly if treatment is abruptly discontinued.

The aim of this study was to address some of these outstanding issues. This investigation was specifically designed to assess asthma control in patients with mild to moderate asthma during and immediately following cessation of regular treatment with the short acting $\beta$ agonist salbutamol, and simultaneously to evaluate the comparative efficacy and safety of the long acting agent salmeterol in a long term placebo controlled study.

\section{Methods}

PATIENTS

One hundred and eighty nine adult patients aged 18-64 years with stable mild to moderate bronchial asthma were enrolled. Inclusion criteria were improvement in forced expiratory volume in one second $\left(\mathrm{FEV}_{1}\right)$ of at least $15 \%$ 15 minutes following inhaled salbutamol 200 $\mu \mathrm{g}$ or its equivalent during the 12 months prior to enrolment and $\mathrm{PC}_{20}$ (provocative concentration eliciting a $20 \%$ fall in $\mathrm{FEV}_{1}$ ) methacholine of $8 \mathrm{mg} / \mathrm{ml}$ or less at a screening visit. For patients already taking inhaled corticosteroids, reversibility of $15 \%$ after methacholine challenge testing was also accepted as an inclusion criterion. Exclusion criteria were current smokers (ex-smokers were required to have stopped for at least 12 months and to have consumed no more than 5 pack years); patients unable to tolerate the withdrawal of oral theophylline, oral $\beta$ agonists or inhaled ipratropium, or who required maintenance oral corticosteroids for adequate asthma control; patients whose average daily consumption of rescue $\beta$ agonist during the run in period was more than 10 puffs per 24 hours despite adequate doses of inhaled corticosteroids; and patients with other significant medical conditions. Patients taking inhaled corticosteroids or cromoglycate were enrolled provided their maintenance dose had not been changed during the previous three months. Patients were required to be compliant with the recording of peak expiratory flow rates (PEFR) and symptoms twice daily in a diary card during the four week run in period prior to randomisation.

\section{STUDY TREATMENTS}

Patients were assigned to receive each of three treatments: salmeterol $50 \mu \mathrm{g}$ twice daily by Diskhaler (four-place; $50 \mu \mathrm{g}$ per blister), salbutamol $400 \mu \mathrm{g}$ four times daily by Diskhaler (eight-place; $400 \mu \mathrm{g}$ per blister), or identical placebo Diskhalers containing lactose. Treatments were administered double blind in a randomised three-way crossover sequence. After a four week run in period each treatment was given for 24 weeks and was followed by a four week washout interval during which both Diskhalers containing placebo were continued. Patients were not informed of the timing of washouts or crossover to the next treatment. Patients were instructed to use both Diskhalers daily throughout the study-both the fourplace and eight-place devices in the morning and late evening and the eight-place Diskhaler at lunch time and in the late afternoon. Salbutamol by metered dose inhaler (MDI) was permitted as needed during each of the treatment periods and washouts, and the amount used was recorded twice daily in a diary. Compliance was calculated by counting the number of returned disks and blisters at each clinic visit.

At the end of the run in period a personalised Action Plan ${ }^{19}$ for the treatment of deteriorating asthma was constructed for each patient based on symptoms and best pre-bronchodilator morning PEFR during the last 14 days of the run in period. Briefly, patients were instructed to commence treatment with either beclomethasone or budesonide in a dose of $1000 \mu \mathrm{g}$ daily or to double their maintenance dose of inhaled corticosteroid if their PEFR fell below $75 \%$ of their "best" value and to continue this regimen until the PEFR returned to $90 \%$ of "best". If their PEFR fell below $60 \%$ of "best" patients were instructed to commence a short course of oral prednisone $(40 \mathrm{mg}$ per day until the morning PEFR rose to $90 \%$ of "best", then $20 \mathrm{mg}$ per day for the same number of days). Adjustments were made where necessary in the interests of patient safety. Patients needing to use inhaled or oral corticosteroids according to their Action Plan continued in the trial. To take account of possible shifts in baseline symptoms and lung function and thus ensure patient safety in the event of an exacerbation, the Action Plan was revised at the end of each washout interval using data from the last 14 days of the washout. Changes in maintenance asthma treatment were only permitted in rare cases where patient safety was at risk. Patients had 24 hour access to an investigator throughout the study. 
Table 2 Criteria for determining minor and major exacerbations

\begin{tabular}{lll}
\hline $\begin{array}{l}\text { Minor exacerbation } \\
\text { Major exacerbation }\end{array}$ & $\begin{array}{l}\text { Asthma score 2 } \\
\text { Asthma score } 3\end{array}$ & $\begin{array}{l}\text { Duration: } 2 \text { or more days } \\
\text { Duration: } 2 \text { or more days OR } 1 \text { day } \\
\text { within the context of a minor } \\
\text { exacerbation }\end{array}$ \\
$\begin{array}{l}\text { Major exacerbation/medical emergency } \\
\text { Conclusion of exacerbation }\end{array}$ & $\begin{array}{l}\text { Asthma score } 4 \\
\text { Asthma score has returned to 0 or } 1\end{array}$ & $\begin{array}{l}\text { Duration: } 1 \text { or more days } \\
\text { Duration: for } 3 \text { or more days, } \\
\text { otherwise exacerbation is deemed to } \\
\text { be continuing }\end{array}$ \\
\hline
\end{tabular}

MEASUREMENTS

The primary outcome measures were morning PEFR, daily asthma score, and exacerbations of asthma and the secondary outcome measures were evening PEFR, diurnal variation in PEFR, symptom scores, rescue bronchodilator use, and $\mathrm{FEV}_{1}$.

\section{Spirometric data}

$\mathrm{FEV}_{1}$ was measured at each of the four weekly clinic visits using identical Spirotech spirometers (Graseby, Smyrna, Georgia, USA) in both centres. Each patient continued to take the study medication as usual prior to the four weekly clinic visits, but dose administration was timed for one hour before the scheduled clinic visit. Supplementary bronchodilator was withheld for six hours prior to clinic visits.

Table 1 Criteria for determining daily asthma score.

\section{Asthma score \\ Score 0: stable asthma}

Score 1: mildly unstable

Score 4: major exacerbation/medical emergency
Score 2: minor deterioration

Score 3: major deterioration

Scoring criteria

Morning PEFR greater than $90 \%$ of run in best value AND number of puffs of supplementary bronchodilator less than 7 per $24 \mathrm{~h}$

OR:

Morning PEFR 76-90\% of run in best value BUT WITHOUT deterioration in any of the symptom scores as listed below

EITHER:

Two or more of the following:

1. Morning PEFR $76-90 \%$ of run in best 1. Morning PEFR $76-90 \%$ of run in best
value

2. Supplementary bronchodilator use: 7 or more puffs per $24 \mathrm{~h}$ greater than rounded mean ${ }^{\star}$ during run in

3. Deterioration in symptom score of 1 point or more compared to rounded mean ${ }^{\star}$ for run in for:

- Daytime or night-time chest tightness/wheeze/dyspnoea OR

- Daytime or night-time cough OR

- Sputum production OR

- Exercise/activity OR

4. Appearance/deterioration in nocturnal wakening

OR:

Morning PEFR $61-75 \%$ of run in best value BUT WITHOUT deterioration in any symptom scores as listed above EITHER

Morning PEFR $61-75 \%$ of run in best value AND two or more of the criteria listed for asthma score 1

OR:

Morning PEFR $40-60 \%$ of run in best value BUT WITHOUT deterioration in any symptom scores listed for asthma score 1

Morning PEFR $40-60 \%$ of run in best value AND two or more of the criteria listed for asthma score 1

EITHER:

Morning PEFR less than $40 \%$ of run in best value irrespective of symptoms OR:

Attendance at general practitioner or hospital emergency department because of severe asthma

${ }^{\star}$ Mean symptom score for last 14 days of run in period, rounded to nearest whole number.
Daily diary data

Patients were instructed to record the best of three peak flow measurements using a miniWright peak flow meter first thing in the morning before taking any inhaled medication and again in the evening irrespective of recent bronchodilator use. Symptoms of daytime and night-time chest tightness/wheeze/dyspnoea, cough, sputum production, exercise/activity, and appearance or deterioration of nocturnal wakening were each recorded and scored on a $0-3$ scale or by a yes/no response where appropriate.

\section{Methacholine challenges}

Methacholine challenges were carried out in a randomly selected subgroup of 80 patients at the beginning of each treatment period and again on days 3 and 8 of each washout interval. A calibrated dosimeter (Morgan Nebicheck; Morgan Instruments, Gillingham, UK) was used, together with a series of Hudson updraft nebulisers, each calibrated fortnightly, for methacholine delivery. After adjustment for nebuliser calibration, exact $\mathrm{PD}_{20} \mathrm{FEV}_{1}$ (provocative dose) values were calculated by interpolation of the dose response curve. Patients were instructed to refrain from taking additional reliever medication for six hours prior to each challenge.

\section{Bronchodilator response}

Bronchodilator response tests were carried out in a randomly selected subgroup of 40 patients immediately before the first dose and exactly three days after the last dose of active study medication for each of the three treatment periods. Where a patient had recently experienced an exacerbation of asthma or had taken additional inhaled or oral corticosteroids, the treatment period or washout interval was extended to ensure that there would be at least 21 days of only regular study medication before the test. Prior to each test patients refrained from taking reliever medication for at least six hours. Testing was carried out at the same time of day for each patient.

Following the baseline measurement of $\mathrm{FEV}_{1}$ and forced vital capacity (FVC) (best of three), patients were given salbutamol using an MDI with a spacer device. Successive doses of $100,100,200,400$ and $800 \mu \mathrm{g}(1,1,2,4$, and 8 puffs) were given at 15 minute intervals. Spirometric values were again measured at 15 , 30, 45, 60, 75, 90 and 120 minutes. From each individual dose response curve the following were calculated: maximum improvement in $\mathrm{FEV}_{1}$ from baseline, area under the curve (AUC) $0-2$ hours, and the dose eliciting 50\% of the maximum response $\left(\mathrm{ED}_{50}\right)$. 
Table 4 Withdrawals during the study

\begin{tabular}{llll}
\hline Reason for withdrawal & Placebo & Salbutamol & Salmeterol \\
\hline Poor asthma control & $1(1)$ & 0 & $2(1)$ \\
Adverse events related to study treatment & 1 & $8(5)^{\star}$ & 0 \\
Adverse events unrelated to study treatment & 2 & 2 & $2(1)$ \\
Poor compliance/social reasons & 6 & 5 & 3 \\
Pregnancy/inadequate contraception & 2 & 1 & 0 \\
Total (n=35) & 12 & 16 & 7
\end{tabular}

Figures in brackets indicate the number of patients who continued to the next treatment period if the adverse event occurred during treatment periods 1 or $2 .{ }^{\star}$ In all cases withdrawal was on account of tremor and/or palpitations.

\section{ASTHMA SCORE}

At each clinic visit an investigator reviewed each daily diary entry and, with reference to a previously devised set of criteria (table 1), a single score (range 0-4) for each 24 hour period was calculated for days on which all diary entries were complete. A score was assigned even if the evening PEFR was missing, but not where other data were absent. Scores were calculated with reference to "best" values for PEFR and also to rounded mean/median values for symptom scores obtained during the last 14 days of the run in period (table 1). For days on which data were missing and scores could not be calculated the last value was carried forward.

\section{EXACERBATIONS}

The asthma score was also used to define the frequency, severity and duration of exacerbations. The asthma score was preferred for this purpose rather than relying on the frequency of additional inhaled or oral corticosteroid use. Criteria for the definition of minor and major exacerbations are shown in table 2 . An exacerbation was considered to have ended where the asthma score had returned to 0 or 1 for a minimum of three consecutive days.

The study was conducted in accordance with the principles of the Declaration of Helsinki on biomedical research. The protocol was approved by the Otago and Canterbury ethics committees and all patients gave written informed consent prior to participation.

\section{STATISTICAL ANALYSIS}

The intention-to-treat population was defined as any randomised patient who received at least one dose of study medication for at least two treatment periods. The efficacy population was restricted to those patients who completed 21 days or more of at least two treatment periods and whose compliance with medication was

Table 3 Baseline data for 165 patients randomised to the study

\begin{tabular}{|c|c|c|}
\hline Age (years) & \multicolumn{2}{|c|}{38 (range 18-64) } \\
\hline Sex $(M: F)$ & \multicolumn{2}{|c|}{$73: 92$} \\
\hline Smoking & \multicolumn{2}{|c|}{$\begin{array}{l}145 \text { non-smokers, } \\
20 \text { ex-smokers }\end{array}$} \\
\hline History of hay fever & \multicolumn{2}{|c|}{$109(66 \%)$} \\
\hline $\mathrm{FEV}_{1}(\%$ predicted $)$ & \multicolumn{2}{|c|}{$79.8 \%(95 \%$ CI 77.2 to 82.5$)$} \\
\hline $\begin{array}{l}\mathrm{PC}_{20} \text { methacholine (geometric } \\
\text { mean) }\end{array}$ & \multicolumn{2}{|c|}{$0.9 \mathrm{mg} / \mathrm{ml}(95 \% \mathrm{CI} 0.69$ to } \\
\hline \multirow{4}{*}{ Regular inhaled corticosteroids } & None & $14(8 \%)$ \\
\hline & $1-400 \mu \mathrm{g}$ & $56(34 \%)$ \\
\hline & $401-1000 \mu \mathrm{g}$ & $59(36 \%)$ \\
\hline & $>1000 \mu \mathrm{g}$ & $36(22 \%)$ \\
\hline
\end{tabular}

$\mathrm{FEV}_{1}=$ forced expiratory volume in one second; $\mathrm{PC}_{20}=$ concentration of methacholine required to provoke a fall in $\mathrm{FEV}_{1}$ of $20 \%$.
$75 \%$ or greater during a treatment period. In addition, where on account of an exacerbation the dose of inhaled corticosteroid was increased for seven or more days, or where oral prednisone was used for three or more days, diary data for these and the subsequent seven days were excluded from the analysis.

Diurnal variation in PEFR was calculated as amplitude \% mean (evening PEFR - morning PEFR) as a percentage of evening PEFR + morning PEFR $/ 2 .{ }^{20} \mathrm{PD}_{20}$ values were log transformed prior to analysis and are expressed as geometric mean values.

For continuous normally distributed end points, between treatment comparisons were carried out by analysis of variance and co-variance (with data from the last 14 days of the run in period as covariate). These models included terms for period and randomisation sequence. Carryover effects were assessed. The other end points were analysed using van Elteren's extension of Koch's method. ${ }^{21}$ Linear trends were fitted to the time by treatment interaction to identify whether time trends differed between treatments. Where appropriate, within treatment comparisons between mean/ median data for the three, seven and 28 day washout intervals and the last 28 days of each treatment period were also carried out to assess washout effects. For asthma score and exacerbations, between treatment comparisons were also undertaken for monthly mean data (weeks $0-4,5-8$, etc.). For exacerbations the time to first exacerbation was analysed according to the method described by Woolson et al. ${ }^{22}$ No adjustments were made for multiple testing.

\section{Results}

One hundred and sixty five patients were randomised to receive treatment. Baseline data for the study population are shown in table 3. Eight patients were retrospectively considered to have violated some aspect of the study protocol and were excluded from the analysis. Results for the remaining 157 patients in the intention to treat population are reported here. Separate analyses for the efficacy population yielded similar results and are not reported further. There were no period or carryover effects. All results are reported as means with $95 \%$ confidence intervals (CI).

During the study there were 35 withdrawals from one or more treatment periods, of whom eight proceeded to the next treatment period (table 4$)$. Compliance with medication $(>75 \%$ of disks/blisters used, as judged by a blister count of unused disks) was $95.4 \%, 97.4 \%$, and $96.3 \%$ for the four-place Diskhaler and $87.4 \%$, $90.4 \%$, and $88.9 \%$ for the eight-place Diskhaler during treatment with placebo, salbutamol and salmeterol, respectively. There was no significant decline in compliance with either of the Diskhaler devices over time.

LUNG FUNCTION

Changes in morning and evening PEFR are shown in fig 1 . Overall, there was a consistent increase in morning PEFR during treatment with salmeterol of $30 \mathrm{l} / \mathrm{min}$ (95\% CI 26 to 35$)$ compared with placebo $(\mathrm{p}<0.001)$. Morning 
Table $5 \mathrm{PD}_{20}$ methacholine values at baseline and during the washout intervals.

\begin{tabular}{lllll}
\hline & $n$ & Baseline & Washout day 3 & Washout day 8 \\
\hline Placebo & 65 & $0.56(0.38$ to 0.82$)$ & $0.58(0.42$ to 0.82$)$ & $0.54(0.38$ to 0.75$)$ \\
Salbutamol & 59 & $0.63(0.44$ to 0.90$)$ & $0.66(0.48$ to 0.90$)$ & $0.72(0.52$ to 1.01$)$ \\
Salmeterol & 60 & $0.52(0.37$ to 0.75$)$ & $0.57(0.41$ to 0.80$)$ & $0.53(0.39$ to 0.71$)$ \\
\hline
\end{tabular}

Results are given as geometric means with $95 \%$ CI.
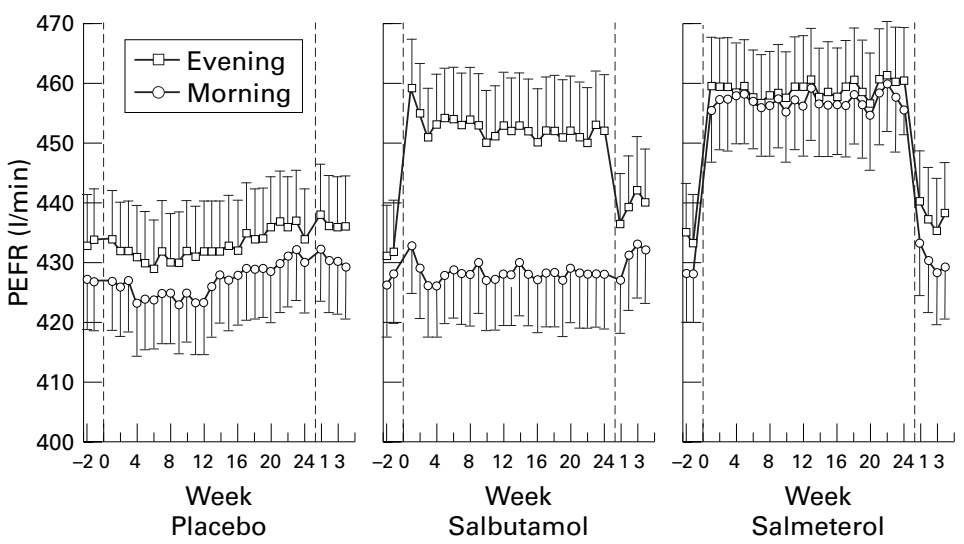

Figure 1 Changes in morning and evening PEFR during the run in, treatment and washout intervals (distinguished by vertical dotted lines).

PEFR values during treatment with salbutamol were not significantly different from placebo. Mean evening PEFR rose by a similar magnitude for each of the two active treatments compared with placebo $(21 \mathrm{l} / \mathrm{min}$ (95\% CI 17 to 26) for salbutamol and $25 \mathrm{l} / \mathrm{min}$ (95\% CI 21 to 30) for salmeterol; $p<0.001)$. The degree of improvement did not change significantly over time during either active treatment. Within and between treatment comparisons for the three, seven, and 28 day washout intervals revealed no evidence of a rebound fall in morning PEFR following treatment with either salbutamol or salmeterol.

Diurnal variation in PEFR decreased from $1.5 \%$ (95\% CI 0.7 to 2.3 ) during treatment with placebo to $0.2 \%$ ( $95 \%$ CI -0.5 to 0.9 ) during treatment with salmeterol $(\mathrm{p}=0.001$ compared with placebo), but increased to $5.9 \%$ (95\% CI 4.9 to 6.9$)$ with salbutamol $(\mathrm{p}<0.001$ compared with placebo). The result for salbutamol was attributable to the increase in evening PEFR during active treatment.

The mean clinic $\mathrm{FEV}_{1}$ one hour after study medication was 2.731 for placebo (95\% CI 2.59 to 2.87 ), 3.041 for salbutamol (95\% CI 2.90 to 3.18 ), and 2.951 for salmeterol $(95 \%$ CI 2.81 to 3.09$) \quad(\mathrm{p}<0.001$ for both active treatments compared to placebo). There was no evidence of change over time, and during the washout intervals the $\mathrm{FEV}_{1}$ did not differ significantly from pretreatment values.

\section{BRONCHIAL HYPERRESPONSIVENESS}

Mean values for $\mathrm{PD}_{20}$ methacholine are shown in table 5. Data were analysed only for those patients who completed a methacholine challenge on all three occasions for any one treatment period-that is, immediately before each treatment period and on days 3 and 8 of the washout interval. There were no significant changes in BHR to suggest either an overall increase in BHR attributable to either active treatment or a rebound increase in BHR at the conclusion of active treatment.

BRONCHODILATOR RESPONSE

Bronchodilator response curves were obtained following placebo, salbutamol, and salmeterol in 34, 37, and 36 patients, respectively. The corresponding mean maximum increases in $\mathrm{FEV}_{1}$ were 0.881 (95\% CI 0.74 to 1.02 ), 0.89 1 (95\% CI 0.78 to 1.00$)$, and 0.861 (95\% CI 0.74 to 0.97 ) (NS). The median $\mathrm{ED}_{50}$ was 87 , 85 , and $84 \mu \mathrm{g}$ of salbutamol for the placebo, salbutamol and salmeterol treatment periods, respectively (NS). Results for the area under the curve (AUC) $\mathrm{FEV}_{1}$ 0-2 hours were similar for all three treatments. Thus, there was no evidence of a treatment related impairment in the acute response to inhaled salbutamol on day 3 of each washout interval.

\section{SYMPTOMS}

The frequency (\% days and nights) with which symptom scores for wheeze/chest tightness and rescue bronchodilator use was equal to zero is shown in table 6 . Treatment with salmeterol resulted in significant reductions in both daytime and night-time wheeze/chest tightness. During treatment with salbutamol significant but less marked reductions occurred in the frequency of daytime but not night-time symptoms.

There were no significant changes in wheeze/ chest tightness with time during either active treatment period. However, during the postsalmeterol washout interval there was a significant rebound increase in the frequency of both daytime and night-time symptoms compared with placebo. This pattern was not observed with salbutamol.

For cough and sputum production no significant treatment effects were observed at any time. For activity score there was significant improvement during treatment with salmeterol $(\mathrm{p}=0.03)$.

RESCUE BRONCHODILATOR USE

During both active treatment periods there was a significant reduction in requirements for rescue bronchodilator, which was greater for salmeterol than for salbutamol (table 6). There was no significant change in the pattern of bronchodilator requirement over time, and during the washout intervals there were no significant differences between treatments or when comparing use during the first three, seven and 28 days of each washout period with the 28 days prior to the washout. Analysis of bronchodilator use on days (24 hours) when the asthma score was 2 or more did not reveal any increase on those days during either of the two active treatment periods compared with placebo.

\section{ASTHMA SCORE}

The percentage of days on which the asthma score was 0,1 and 2 or more is shown in table 7. There was a highly significant improvement in the asthma score during treatment with salmeterol compared with placebo $(\mathrm{p}<0.001)$. 


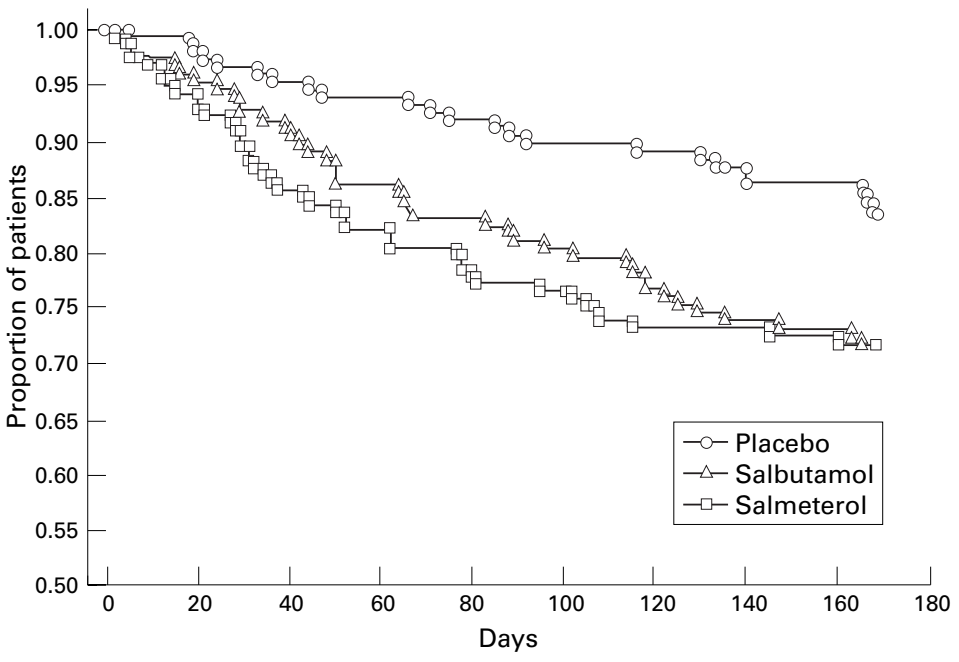

Figure 2 Kaplan-Meier plot showing the proportion of patients who remained free of exacerbations during each treatment period (days). This was significantly greater for salmeterol than for salbutamol compared with placebo in subjects for whom paired comparisons were possible $(n=146 ; p=0.008)$.

There was no overall difference between salbutamol and placebo. During the postsalmeterol washout interval there was a significant decrease in the percentage of days with an asthma score of 0 compared with placebo. This change was not observed following salbutamol. The change following salmeterol coincided with a significant increase in the percentage of days with a score of 1 - that is, minor degrees of instability - but not with a score 2 or more. Over the $0-24$ week time interval there were significant differences in the trends over time in the percentage of days with an asthma score of 2 or more: the frequency decreased for placebo $(\mathrm{p}<0.001)$, increased for salbutamol $(\mathrm{p}<0.001)$, but did not change for salmeterol.

EXACERBATIONS

There were 11 occasions on which emergency medical help was required by a study patient, three during treatment with placebo, two with salbutamol, and six with salmeterol. The total

Table 6 Symptoms and bronchodilator use. Within treatment comparisons using data for weeks 21-24 as baseline were also used for the analysis of washout effects

\begin{tabular}{lllll}
\hline & & Placebo & Salbutamol & Salmeterol \\
\hline $\begin{array}{l}\text { Day time } \\
\text { Wheeze/tightness (\% days with } \\
\text { score = 0) }\end{array}$ & Run in & 61.3 & 62.0 & 64.4 \\
& Weeks 0-24 & 63.6 & $72.3^{\star}$ & $79.8 \dagger$ \\
& Weeks 21-24 & 64.3 & $72.4^{\star}$ & $80.1 \dagger$ \\
& Washout 0-4 & 65.8 & 62.3 & $60.3 \#$ \\
$\begin{array}{l}\text { Rescue bronchodilator (\% days } \\
\text { with 0 puffs) }\end{array}$ & Run in & 54.6 & 53.4 & 57.9 \\
& Weeks 0-24 & 59.8 & $72.5^{\star}$ & $79.3 \dagger$ \\
& Weeks 21-24 & 60.7 & $73.7^{\star}$ & $79.3 \dagger$ \\
& Washout 0-4 & 61.1 & 59.3 & 58.7 \\
$\begin{array}{l}\text { Night-time } \\
\text { Wheeze/tightness (\% nights with }\end{array}$ & Run in & 75.5 & 76.0 & 78.2 \\
score = 0) & Weeks 0-24 & 75.6 & 77.8 & $87.7 \dagger$ \\
& Weeks 21-24 & 76.7 & 78.4 & $89.4 \dagger$ \\
& Washout 0-4 & 79.0 & 76.5 & $75.4 \ddagger$ \\
Rescue bronchodilator (\% nights & Run in & 79.3 & 76.8 & 78.0 \\
with 0 puffs) & Weeks 0-24 & 77.8 & $86.5^{\star}$ & $92.2 \dagger$ \\
& Weeks 21-24 & 78.3 & $88.1^{\star}$ & $92.7 \dagger$ \\
& Washout 0-4 & 80.2 & 80.6 & 80.8 \\
\hline
\end{tabular}

${ }^{\star} \mathrm{p}<0.05$, salbutamol better than placebo. $\mathrm{tp}<0.001$, salmeterol better than placebo $\# p=0.005$, salmeterol worse than placebo $\ddagger \mathrm{p}=0.03$, salmeterol worse than placebo
Table 7 Asthma score: percentage of days with score 0 (stable asthma), score 1 (mildly unstable asthma), and score 2 or more (minor or major deterioration). Data for weeks 21-24 were also used for the analysis of washout effects

\begin{tabular}{lllll}
\hline & Weeks & Score $=0$ & Score $=1$ & $\begin{array}{l}\text { Score }=2 \\
\text { or more }\end{array}$ \\
\hline Placebo & $0-24$ & 77.4 & 20.4 & 2.3 \\
& $0-4$ & 78.1 & 19.6 & 2.3 \\
& $21-24$ & 78.4 & 20.6 & 1.0 \\
& Washout & 80.5 & 16.9 & 2.6 \\
& $0-4$ & & & \\
Salbutamol & $0-24$ & 76.5 & 20.8 & 2.7 \\
& $0-4$ & 76.1 & 21.7 & 2.2 \\
& $21-24$ & 77.1 & 20.0 & 2.9 \\
& Washout & 78.6 & 23.1 & 2.1 \\
& $0-4$ & & & \\
Salmeterol & $0-24$ & $87.4^{\star}$ & $11.9 \star$ & 0.6 \\
& $0-4$ & 88.6 & 10.8 & 0.6 \\
& $21-24$ & 88.6 & 11.0 & 0.4 \\
& Washout & $74.0 \dagger$ & $23.1 \dagger$ & 2.1 \\
& $0-4$ & & & \\
\hline
\end{tabular}

${ }^{\star} \mathrm{p}=0.001$, salmeterol better than placebo.

$\mathrm{tp}=0.02$, salmeterol worse than placebo.

number of exacerbations (major and minor combined) was 97 during treatment with placebo, 92 with salbutamol, and 35 with salmeterol. The proportion of patients who did not have exacerbations with respect to time is shown in fig 2. Details of minor and major exacerbations are shown in table 8 .

Treatment with salmeterol resulted in a highly significant decrease in the rate of exacerbations (number per patient per year) compared with placebo by $70 \%(\mathrm{p}=0.008)$, $45 \%(p=0.03)$, and $63 \%(p=0.0001)$ for minor, major and total exacerbations, respectively, whereas salbutamol had no significant effect $(9.3 \%$ decrease, $27.5 \%$ increase, and $1.5 \%$ increase, respectively; NS).

During washout intervals there were no significant differences between treatments for either minor or major exacerbation rates. There was no significant change in the pattern of exacerbations over time. Although there were no significant differences in the duration of individual exacerbations between treatments, the cumulative time spent in major exacerbation was significantly greater for salbutamol than for placebo $(p=0.02)$.

ADDITIONAL CORTICOSTEROID USE

The percentage of patients who temporarily increased their inhaled corticosteroid dose according to their Action Plan was $38.7 \%$, $29.1 \%$ and $21.1 \%$ during treatment with placebo, salbutamol and salmeterol, respectively ( $p=0.001$, salmeterol less than placebo). The mean number of days on which these patients used increased doses was 22.1 (95\% CI 12.8 to 31.4 ), 23.6 (95\% CI 15.9 to 31.3 ), and 11.7 (95\% CI 7.4 to 16.0 ) days, respectively (NS). The intervention rate did not change with time and the pattern of use was identical for each of the washout intervals.

The percentage of patients who used one or more short courses of prednisone was $12.3 \%$, $15.2 \%$, and $10.5 \%$ for placebo, salbutamol, and salmeterol, respectively (NS). The mean number of days on which these patients used prednisone was 13.5 (95\% CI 8.0 to 18.9 ), 19.5 (95\% CI 8.7 to 30.4 ), and 13.5 (95\% CI 7.5 to 19.5 ) days, respectively (NS). 
Table 8 Exacerbation data

\begin{tabular}{|c|c|c|c|}
\hline & Placebo & Salbutamol & Salmeterol \\
\hline \multicolumn{4}{|c|}{ Number during each treatment period } \\
\hline Total & 97 & 92 & 35 \\
\hline Minor & 69 & 58 & 20 \\
\hline Major & 28 & 34 & 15 \\
\hline \multicolumn{4}{|c|}{ Number of patients without exacerbations during each period (\%) } \\
\hline Total & 72.1 & 73.5 & $84.9 \dagger$ \\
\hline Minor & 76.6 & 76.8 & $89.5 \dagger$ \\
\hline Major & 88.3 & 89.4 & $91.5^{\circ}$ \\
\hline \multicolumn{4}{|c|}{ Corrected exacerbation rate (number per patient per year) } \\
\hline Total & $1.37(1.11$ to 1.67$)$ & $1.39(1.12$ to 1.71$)$ & $0.51^{\#}(0.35$ to 0.70$)$ \\
\hline Minor & $0.97(0.76$ to 1.23$)$ & $0.88(0.67$ to 1.13$)$ & $0.29^{\#}(0.18$ to 0.45$)$ \\
\hline Major & $0.40(0.26$ to 0.57$)$ & $0.51(0.36$ to 0.72$)$ & $0.22 \ddagger(0.12$ to 0.36$)$ \\
\hline \multicolumn{4}{|c|}{ Mean duration per exacerbation (days) } \\
\hline Total & $4.4(3.6$ to 5.2$)$ & $4.5(3.8$ to 5.2$)$ & $3.6(2.6$ to 4.6$)$ \\
\hline Minor & $4.0(3.4$ to 4.7$)$ & $3.7(3.0$ to 4.4$)$ & $2.8(2.3$ to 3.3$)$ \\
\hline Major & $5.4(3.2$ to 7.6$)$ & $5.8(4.5$ to 7.1$)$ & $4.7(2.7$ to 6.8$)$ \\
\hline \multicolumn{4}{|c|}{ Mean time spent in exacerbation per patient (days) } \\
\hline Total & $10.0(7.2$ to 12.8$)$ & $10.3(6.1$ to 14.5$)$ & $5.5(2.8$ to 8.2$)$ \\
\hline Minor & $7.7(5.5$ to 9.9$)$ & $6.2(4.6$ to 7.8$)$ & $3.5(2.2$ to 4.6$)$ \\
\hline Major & $8.4(5.2$ to 11.6$)$ & $12.3^{\star}(4.2$ to 20.4$)$ & $5.5(1.8$ to 9.3$)$ \\
\hline
\end{tabular}

Figures in brackets are $95 \%$ confidence intervals.

${ }^{\star} \mathrm{p}=0.02$, salbutamol longer than placebo.

$\mathrm{tp}=0.009$, salmeterol better than placebo (both results).

$\neq \mathrm{p}=0.03$, salmeterol lower than placebo.

$\# \mathrm{p}=0.0001$, salmeterol lower than placebo.

\section{Discussion}

This study has shown that, in patients with mild to moderate bronchial asthma, the use of regular inhaled salmeterol resulted in significant improvements in asthma control as measured by the daily asthma score and the frequency of minor and, to a lesser extent, major exacerbations. There was a $63 \%$ reduction in the total exacerbation rate during treatment with salmeterol, and this was associated with a mean increase in morning PEFR of 30 $1 /$ min compared with placebo. By contrast, the overall frequency of exacerbations with salbutamol was not significantly different from placebo, although there was some evidence that, over time, control of asthma may have been compromised.

Our results are similar to those of other studies $^{151623}$ in which regular treatment with salmeterol resulted in improvements in lung function and asthma symptoms, and they confirm a more recent report that asthma exacerbation rates are also reduced when a long acting $\beta$ agonist is added to inhaled corticosteroid therapy. ${ }^{24}$ The present study was designed to include a rigorous evaluation of the effects of treatment on day-to-day asthma control as well as on both minor and major exacerbations. This was a deliberate aim given concerns that, despite improved bronchodilatation and symptom control, the frequency or severity of asthma exacerbations either during or immediately after regular treatment with a long acting $\beta$ agonist might be increased. For this reason exacerbation rates were calculated from patient diaries whether or not they actually intervened with additional treatment. This was to overcome potential inaccuracies which might arise if the frequency with which patients acted on their self-management plan was used as a study end point; intervention by patients with additional treatment may be influenced by a number of factors other than asthma severity. Daily asthma scores were also calculated because of the relative infrequency of exacerba- tions, and because minor degrees of deterioration might not otherwise be detected. Using either approach there was no evidence to suggest that asthma control deteriorated during or after treatment with salmeterol. Indeed, salmeterol had a beneficial effect principally by reducing the frequency of minor exacerbations ( $70 \%$ reduction). Its effect on major exacerbation rates was less marked ( $45 \%$ reduction). In keeping with this was the finding that regular salmeterol did not reduce the overall requirement for oral prednisone or the total duration of prednisone use. Although this latter result contrasts somewhat with that of the FACET study, ${ }^{24}$ the message is a consistent onenamely, that adequate anti-inflammatory therapy is a more reliable means of achieving asthma control, especially in patients who are susceptible to major exacerbations.

The frequency of emergency events was greater during the salmeterol treatment period than for the other two treatment periods combined. Although the number of events was very small, the pattern is similar to that reported by Castle et al for asthma mortality during long term salmeterol treatment. ${ }^{13}$ Given that salmeterol had no adverse impact on exacerbations rates or prednisone use, this finding raises the possibility that the use of a long acting $\beta$ agonist may mask the development of a major exacerbation and delay intervention. Further studies are required so that the strategy for selfmanagement plans may, if necessary, be modified to take account of the effect of long acting $\beta$ agonists.

During treatment with salbutamol there were significant improvements in daytime symptoms and evening PEFR, together with a reduction in rescue bronchodilator requirements, but overall control of asthma was no different from placebo. For the entire 24 week treatment interval the frequencies of daily asthma scores 0,1 and 2 or more were similar to placebo, and likewise the frequency of both minor and major exacerbations was not significantly different. Nevertheless, there was a significant month-on-month increase in the percentage of days with an asthma score of 2 or more, reflecting a gradual decline in asthma control. During weeks $21-24$ of the salbutamol treatment period $9.4 \%$ of patients had one or more exacerbations, compared with $4.1 \%$ for placebo $(p=0.013)$ and $3.4 \%$ for salmeterol. In addition, the overall time spent in major exacerbations by individual patients was significantly longer during treatment with salbutamol $(12.3$ days, $p=0.02)$ than for the other two treatment periods (placebo 8.4 days, salmeterol 5.5 days) and, although not statistically significant, the number of major exacerbations, the number of patients who used oral prednisone, and the total duration of prednisone use were greatest during treatment with salbutamol. Although this pattern of outcomes may have occurred by chance, it may represent an underlying trend towards poorer asthma control during long term treatment with salbutamol which, when measured in terms of overall exacerbation rates, this and other studies have been insufficiently powerful ${ }^{25}$ or of 
insufficient duration ${ }^{26}$ to detect. This raises the possibility that, in groups of patients who use regular or higher doses of inhaled salbutamol for longer periods of time, control of asthma, particularly during exacerbations, may be adversely affected. ${ }^{27}$

Our study was designed to identify possible "rebound" effects when either of the two active agents was discontinued. This phenomenon has been described for BHR following withdrawal of regular treatment with short acting $\beta$ agonists $^{6}$ but not with the long acting agents. ${ }^{18}{ }^{28}$ In the present study there was no evidence of rebound changes in PEFR, $\mathrm{PD}_{20}$ methacholine, or rescue bronchodilator requirements following either active treatment, and the frequency of minor and major exacerbations was similar during each of the washout intervals. Only one significant result emerged-namely, that there was an increase in symptoms of wheeze/chest tightness during the post-salmeterol washout and this was reflected in a significant reduction in the number of days with an asthma score of 0 . We interpret this finding as indicating that patients perceive the loss of the benefit of salmeterol on wheeze/chest tightness when it is discontinued, but that this symptomatic change is not associated with clinically important deterioration in asthma control or the need for additional bronchodilator.

When used regularly, both short and long acting $\beta$ agonists may result in tolerance to the protective effects of single doses of inhaled $\beta$ agonist against exercise-induced bronchospasm, non-specific bronchoconstrictors, and allergen. ${ }^{29}$ In addition, following regular inhaled salmeterol, tolerance to the bronchodilator effects of salbutamol has been described. ${ }^{18}$ The clinical importance of each of these findings has not been established.

In our study tolerance to the bronchodilator action of increasing doses of salbutamol was not observed following regular salmeterol or salbutamol in the patients who undertook dose-response studies, although we recognise that this result may have been affected by the fact that $\beta$ agonist was still permitted to be used as needed during the placebo treatment period against which comparisons were made. Likewise, we could find no indirect evidence to suggest that tolerance was occurring. Analysis of rescue bronchodilator requirements on days when the asthma score was 2 or more-that is, when there was clinically important deterioration-did not reveal any treatment related increase. Thus, the speculation ${ }^{17}$ that salmeterol induced tachyphylaxis might increase the need for rescue bronchodilator during episodes of acute deterioration of asthma has not been demonstrated in this study. Furthermore, there was no evidence that the frequency of minor or major exacerbations or of days on which the asthma score was 2 or more increased with time during treatment with salmeterol. For salbutamol the evidence was less clear cut. The observation that the frequency of days on which the asthma score was 2 or more increased over time may possibly have resulted from the development of tolerance.
Our results suggest important differences between the short acting and the long acting agents salbutamol and salmeterol as far as asthma control is concerned. The reasons for this appear to be unrelated to differences in their duration of action and are difficult to explain. It has been suggested that differences in intrinsic pharmacological properties are responsible for differing outcomes between the $\beta$ agonists. ${ }^{30}$ The results of this study endorse the shift in emphasis of current guidelines for the management of chronic, mild to moderate asthma in adults. They confirm that regular use of salmeterol (together with as needed use of a short acting agent) confers significant benefit on the control of asthma, particularly among patients who are still symptomatic despite taking inhaled corticosteroids, ${ }^{9-11}$ although without having a significant impact on major exacerbation rates. For salbutamol, despite improvement in daytime symptoms, overall asthma control was not significantly improved when this drug was given regularly. It is therefore appropriate to reserve short acting $\beta$ agonists for use only as needed for the relief of breakthrough asthma symptoms. Indeed, subtle but significant changes in the asthma score and exacerbation rates over the six month salbutamol treatment period raise concerns that, consistent with earlier findings using fenoterol, ${ }^{2}{ }^{3}$ regular use of this short acting agent may affect asthma adversely over the longer term.

We are grateful to patients and the referring general practitioners in the provinces of Otago and Canterbury for their commitment this sty. We acknowney for her assistance with respiratory laboratory quality control measures and the logistic support of Loretta Jacques, Gillian Brooks, Louise Johnson, Jayne Stuart and other GlaxoWellcome staff (UK and New Zealand) in carrying out this study. The protocol was designed by the authors and was independently reviewed by the Health Research Council of New Zealand. Independent analyses were conducted by both the authors and GlaxoWellcome. The study was funded by GlaxoWellcome Research and Development (UK)

1 Grainger J, Woodman $\mathrm{K}$, Pearce $\mathrm{N}$, et al. Prescribed fenoterol and death from asthma in New Zealand, 1981-1987. A further case-control study. Thorax 1991;46:105-11

2 Sears MR, Taylor DR, Print CG, et al. Regular inhaled betaagonist treatment in bronchial asthma. Lancet 1990;336: $1391-6$.

3 Taylor DR, Sears MR, Herbison GP, et al. Regular inhaled beta-agonist in asthma: effects on lung function and exacerbations. Thorax 1993;48:134-8.

4 Taylor DR, Sears MR. Regular beta-adrenergic agonists. Evidence not reassurance is what is needed. Chest 1994;106:552-9.

5 Taylor DR, Sears MR, Cockcroft DW. The beta-agonist controversy. Med Clin North Am 1996;80:719-47.

6 Vathenen AS, Knox AJ, Higgins BJ, et al. Rebound increase in bronchial responsiveness after treatment with inhaled in bronchial responsiveness after

7 Sears MR. Epidemiological trends in asthma. Can Respir $\mathcal{F}$ 1996;3:261-8.

8 Tattersfield AE. Clinical pharmacology of long-acting betareceptor agonists. Life Sci 1993;52:2161-9.

9 Woolcock A, Lundback B, Ringdal N, et al. Comparison of addition of salmeterol to inhaled steroids with doubling of the dose of inhaled steroids. Am $\mathcal{F}$ Respir Crit Care Med 1996;153:1481-8

0 Greening AP, Ind PW, Northfield M, et al. Added salmeterol versus higher dose corticosteroid in asthma patients with symptoms on existing inhaled corticosteroid. Lancet 1994; 344:219-23.

11 Wilding P, Clark M, Coon JT, et al. Effect of long-term treatment with salmeterol on asthma control: a doubleblind, randomised cross-over study. BMF 1997;314:14416.

12 Bone RC. A word of caution regarding a new long-acting bronchodilator. FAMA 1994;271:1447-8.

13 Castle W, Fuller R, Hall J, et al. Serevent nationwide surveillance study: comparison of salmeterol with salbutamol in asthmatic patients who require regular bronchodilator treatment. BMF 1993;306:1034-7. 
14 Mann RD, Kubota K, Pearce G, et al. Salmeterol: a study by prescription-event monitoring in a UK cohort of 15,407 prescription-event monitoring in a UK coh

15 Pearlman DS, Chervinsky P, LaForce C, et al. A comparison of salmeterol with albuterol in the treatment of mild to moderate asthma. N Engl f Med 1992;327:1420-5.

16 D'Alonzo GE, Nathan RA, Henochowicz S, et al. Salmeterol xinafoate as maintenance therapy compared with albuterol in patients with asthma. $\mathcal{F A M A}$ 1994;271:1412-6.

17 Grove A, Lipworth BJ. Bronchodilator subsensitivity to salbutamol after twice daily salmeterol in asthmatic patients. Lancet 1995;346:201-6.

18 Cheung D, Timmers MC, Zwinderman AH, et al. Long-term effects of a long-acting $\beta_{2}$ adrenoceptor agonist, salmeterol, on airway hyperresponsiveness in patients with mild asthma. N Engl f Med 1992;327:1198-1203.

19 Town GI, Hodges ID, Wilkie AT, et al. A community wide promotion of asthma self-management in New Zealand. Patient Education and Counselling 1995;26:219-24.

20 Higgins BG, Britton JR, Chinn S, et al. The distribution of peak expiratory flow variability in a population sample. $A m$ peak expiratory flow variability in a
Rev Respir Dis 1989;140:1368-72.

21 Koch GG. The use of non-parametric methods in the statistical analysis of the two-period change-over design. Biomet rics 1972;28:577-84.

22 Woolson RF, O'Gorman TW. A comparison of several tests for censored paired data. Stat Med 1992;11:193-208.
23 Boulet LP, Laviolette M, Boucher S, et al. A twelve-week comparison of salmeterol and salbutamol in the treatment of mild-to-moderate asthma: a Canadian multicenter study. F Allergy Clin Immunol 1997;99:13-21.

24 Pauwels RA, Lofdahl CG, Postma DS, et al.Effect of inhaled formoterol and budesonide on exacerbations of asthma. $N$ Engl f Med 1997;337:1405-11.

25 Drazen JM, Israel E, Boushey HA, et al. Comparison of regularly scheduled with as-needed use of albuterol in mild asthma. N Engl f Med 1996;335:841-7.

26 Chapman KR. Kesten S, Szalai JP. Regular vs.as-needed inhaled salbutamol in asthma control. Lancet 1994;343: 1379-82.

27 Suissa S, Blais L, Ernst P. Patterns of increasing beta-agonist use and the risk of fatal or near-fatal asthma Eur Respir $\mathcal{F}$ 1994;7:1602-9.

28 Booth HK, Fishwick R, Harkawat G, et al. Changes in methacholine induced bronchoconstriction with the longacting $\beta_{2}$ agonist salmeterol in mild to moderate asthmatic patients. Thorax 1993;48:1121-4.

29 Cockcroft DW, Swystun VA. Functional antagonism: tolerance produced by inhaled $\beta_{2}$ agonists. Thorax $1996 ; 51$ : 1051-6.

30 Dickey BF, Clark RC, Barber R. Partial $\beta_{2}$ agonists and their impartial assessment. Chest 1996;110:1131-2. 